\title{
How gamification can drive customer loyalty
}

\author{
Prof. Dr. Marco Schmäh \\ ESB Business School \\ Lehrstuhl für Marketing \& Sales Management \\ Email: Marco.Schmaeh@Reutligen-University.de \\ Germany
}

Alexander Leon Ritz

Email: alexander.leon.ritz@gmail.com

Germany

\section{ABSTRACT}

This paper intends to give an insight on how to develop a customer loyalty-focused gamification concept, that will trigger intrinsic motivation and hence strengthen customer loyalty, using the mobility industry as an example. The authors conducted explorative expert interviews to create a cross-industry process chart that guides the generic development of a customer loyalty-focused gamification concept.

\section{Introduction}

In recent years, gamification has become a familiar concept of both improving already existing business solutions and designing new ones. Scientists and experts expect gamification to revolutionize the status quo of product development and to become a multi-billion U.S. Dollar market within a few years (Arshad, Baharun, \& Zaidin, 2019; Costello, 2019; Zhao \& Guo, 2019). Furthermore, various scientists emphasize the potential of gamification concepts to drive customer loyalty (Eppmann, Bekk, \& Klein, 2018; Hwang, 2018; Nobre \& Ferreira, 2017; Noorbehbahani, Salehi, \& Jafar Zadeh, 2019; Paharia, 2013; Sever, Sever, \& Kuhzady, 2015; Sigala, Toni, Renzi, Pietro, \& Mugion, 2019; Xi \& Hamari, 2019). Because of the constantly growing competition and the high costs of customer acquisition, it is often more effective to bind existing customers instead of trying to attract new ones (Kim \& Ahn, 2017; Xin, Zuo, Iida, \& Aziz, 2018). However, many companies have not found the right approach yet (Gupta $\&$ Gomathi, 2017). The modern customers of the digital world strive for meaningful interactions with business solutions. This requires a new business strategy on how to motivate customers. One research, carried out in the software industry, concluded that business solutions involving joyful elements lead to increased use and therefore easier bind customers (Draper, 1999). The gamification approach, as an enjoyment incentive, correlates with business objectives like customer motivation, experience, behavior, and engagement (Eppmann, Bekk, \& Klein, 2018; Huotari \& Hamari, 2017; Nobre \& Ferreira, 2017). A gamified experience often acts as a catalyst for awakening and driving purposeful customer behavior in different aspects of life (Deterding, 2019; Noorbehbahani, Salehi, \& Jafar Zadeh, 2019).

\section{Relevance of customer loyalty in the mobility industry}

For several years now the mobility industry is subjected to major disruptions. Those are driven by rapid urbanization, electrification, connected vehicles, and economic interdependencies, among many other examples (Fitzgerald, Avramakis, Anchen, \& Raverkar, 2019; Peinen, Böhmer, \& Lindemann, 2018). Weak demand and, consequently, lack of profitability forces mobility service companies to rethink their product range and particularly product functionalities (Fitzgerald et al., 2019; Kortum, Schönduwe, Stolte, \& Bock, 2016). Empirical studies on mobility service companies pointed out a direct connection between customer retention and higher profitability due to an increase in the utilization frequency (Fitzgerald et al., 2019; Kortum et al., 2016). This raises the question, whether the gamification approach is a suitable tool to increase customer loyalty in the mobility industry.

\section{Methodology}

To give an extensive insight on how to develop a customer loyalty-focused gamification concept an explorative interview with 7 experts has been conducted. The choice of experts is based on quota sampling (Saunders, Lewis, \& Thornhill, 2016) to provide respective expertise on different aspects regarding gamification. For this reason, each quota is represented by a different expert: (E1) university lectures, (E2) academic researchers, (E3) industry experts, (E4) consultants, (E5) technical product owners, (E6) business product owners, and (E7) entrepreneurs of a gamified business solution in the mobility industry. Table 1 provides an overview of the experts' qualifications and experiences. 


\begin{tabular}{|l|ll|}
\hline E1 & $\checkmark$ & Professor at a German university \\
& $\checkmark$ & Visiting professor of two different European universities \\
\hline E2 & $\checkmark$ & Ph.D. at a German university in the area of gamification \\
& $\checkmark$ & Member of the Gamification Group at Tampere University \\
\hline E3 & $\checkmark$ & Former Head of Live Game Design at a big gaming firm \\
& $\checkmark$ & Specialist in gamification, game design, and monetization \\
\hline E4 & $\checkmark$ & Founder of the first gamification consultancy in Germany \\
& $\checkmark$ & International gamification expert and keynote speaker \\
\hline E5 & $\checkmark$ & Head of product of a gamified mobility solution \\
& $\checkmark$ & Technical expert in the area of blockchain-based business solutions \\
\hline E6 & $\checkmark$ & Product owner of a gamified mobility solution \\
& $\checkmark$ & User experience designer \\
\hline E7 & $\checkmark$ & Founder and product owner of a gamified mobility solution \\
& $\checkmark$ & Scrum master \\
\hline
\end{tabular}

Table 1. Experiences of interviewed experts.

Source: Own diagram.

\section{Findings on the mobility industry}

Each of the interviewed experts named different success factors related to customer motivation in the mobility industry, such as time and money-saving or an increase of convenience and mobility variety. E3 believes that keeping the success factors in mind enhances the success of a gamification concept integrated into the mobility industry. Furthermore, E1 claims: "We need frictionless well-functioning systems first of all". E4 emphasizes the general requirement for gamification concepts to be the freedom of choice because a gamified experience requires a choice of action. E4 provides an example of a train ride where customers expect to optimize for example time, money, and convenience. But if a "more exciting journey [was created], that made the passengers asking to slow down the train because the ride is so interesting"(E4), a great customer experience would be created, and customer loyalty would be positively influenced.
The interviewed experts agree on a wide range of different gamification elements and therefore name gamification elements such as points, levels, achievements, challenges, and leader boards (E1-E7). E2 believes that challenges are joyful and enhance learning processes. Overcoming challenges by independent decision-making makes customers feel competent and powerful. E4 agrees on involving challenges as this gives customers the impression of being in control. Because true engagement, retention, and loyalty come from intrinsic motivation, which can only be born out of genuine emotions. Therefore, intrinsic motivation is key, which makes the customers resistant to competitors' business solutions. To trigger intrinsic motivation, E4 recommends the Triple $R$ combination: Reframing rewards as resources. The underlying idea is that loyalty only comes from doing something for the sake of doing it, which only can be accomplished by intrinsic motivational factors. Illustration 3 visualizes E4's cycle of intrinsic motivation.

2 Challenges put customers into control

(1) Gamification concepts motivate customers to act in a certain behavior

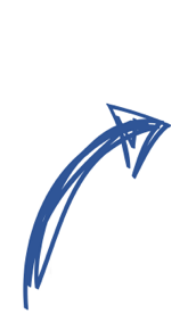

- 'b=

MOTIVATION
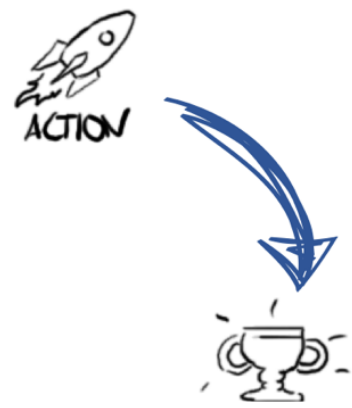

Resource
3 Good Behavior will be awarded with resources instead of rewards

Illustration 1. Cycle of intrinsic motivation. 


\section{(C) Center for Promoting Education and Research (CPER) USA}

WWW.cpernet.org

The cycle begins with the design of a (1) gamification concept. The trigger of the customer motivation is driven by (2) challenges, which are aligned with the customers' intrinsic motivation, the company objective, and the specific player types of the target group. Good behavior, measured by the passing of a challenge, leads to an award characterized by a (3) resource that nurtures the customer motivation and enables the passing of the upcoming challenge. This will result in a continuous user flow.

Additionally, a holistic gamification concept, which involves the interconnection of individual gamification elements, is required. The interviewed experts name user flows, currencies, and logical relationships to integrate single gamification elements. The underlying currencies are based on mathematical and logical relationships of the individual gamification elements, that can be integrated into the user flow. E6 suggests analyzing relevant user flows of business solutions first. After that a validation is necessary, that defines which gamification element can be integrated at what customer touchpoint to enhance the customer's gamification experience the most. Illustration 1 provides an example of a user flow of a mobility service platform.

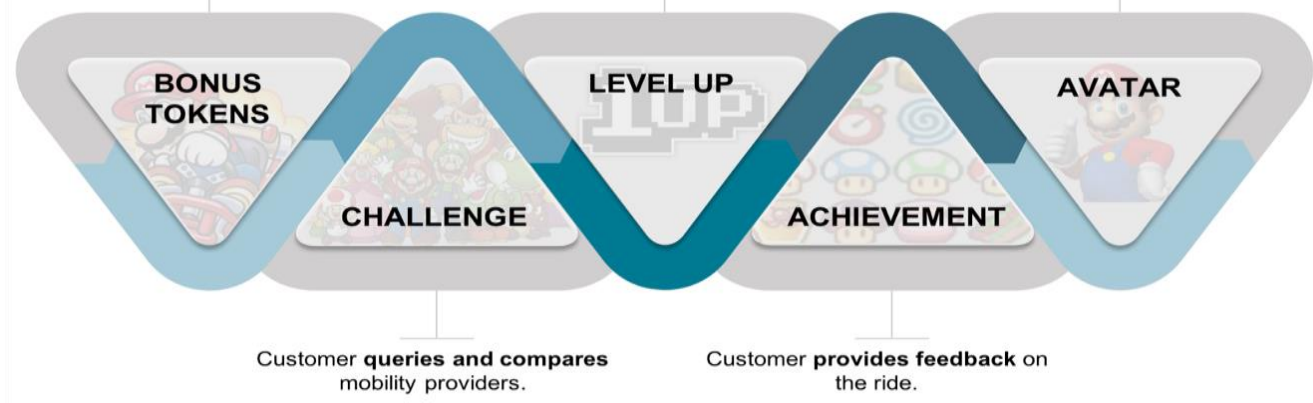

Illustration 2. Exemplary user flow of a customer in the mobility industry Source: Own diagram.

E3 gives an example for a user flow of the mobility industry according to illustration 1: If a customer wants to get from point $\mathrm{A}$ to point $\mathrm{B}$, his journey might start with driving through the outer district of a city. Here driving by car might be regarded at first sight as advantageous. A gamified business solution could incentivize them to explore the district by using event-based gamification elements, such as achievements or badges. Furthermore, a gamified business solution could offer various mobility solutions to the customer, that convince them to change the mode of transportation, because for instance the traffic has unexpectedly increased or other modes of transportation are faster, cheaper, more convenient, etc. Of course, the above-mentioned gamification elements can be integrated at different steps of the user flow by the holistic business concept.

However, it can be challenging to define a certain target group in the mobility industry, depending on the business solution. E2 highlights that anyone can be a potential customer, who uses bicycles, cars, buses, trains, or airplanes just any means of transportation. According to E3, this applies to the mobility industry, as well as any other industry. On the other hand, a gamification concept that does not specify its target group and hence tries to build one game for each and every one is a rather unrealistic scenario (E2).

Finally, it should be noted, that the findings of the research do not conclude any differences between the industries regarding how to develop an individual gamification concept. E3 argues that psychological factors are often identical. Consequently, gamification elements appeal to customers regardless of the industry. E4 remarks, that gamification targets human behavior. So, even if you pick a different industry, human behavior and psychological factors will always be the target of any gamification strategy.

\section{Findings on the development process}

Illustration 2 presents a generic, cross-industry overview of the relevant gamification development steps.

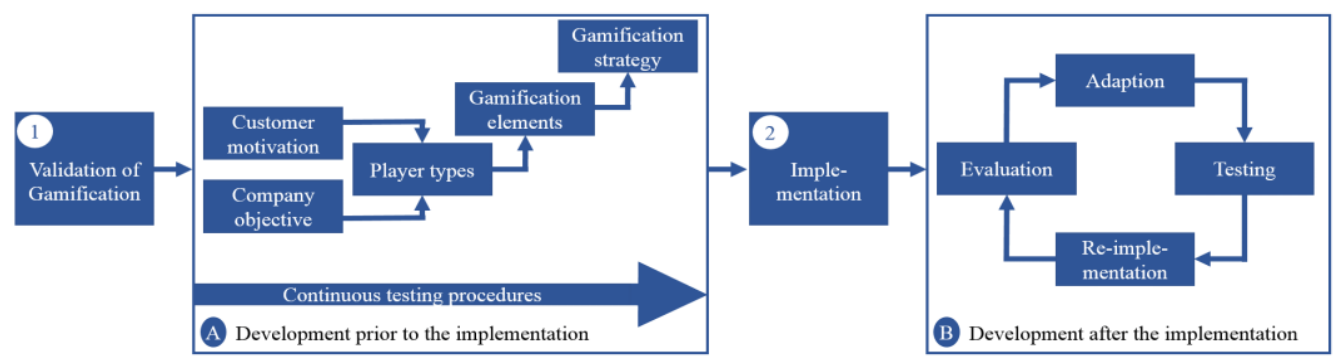

Illustration 3. Cross-industry process chart. 


\section{(C) Center for Promoting Education and Research (CPER) USA}

WWW.cpernet.org

The process chart is divided into two sections: The development of a gamification concept before and after the implementation of the gamification concept. Before both sections, a milestone will be given that validates if the development process should be continued or aborted.

\section{Milestone 1: Preliminary analysis}

The starting point of the development of a gamification concept is a business solution that eventually can be enhanced by using gamification (elements). The preliminary question is whether the functionality of the business solution allows putting the customer in control so that they can choose between several options at different customer touchpoints. In the next step, the development team reviews their required capabilities for building a gamification concept, such as knowledge in psychology, human motivation, game design, and customer experience. If the business solution allows for customers to be put in control and the required capabilities are covered by the development team, subsequently, the gamification development process can be initialized.

Section A: Development steps before the implementation

At the beginning of the gamification development process, the customer motivation needs to be carefully analyzed and compared to the company objective. To measure the effectiveness of the implemented gamification concept the definition of the company objective requires to be as specific as possible. First-level company objectives such as revenue or profit increase are challenging to be explained solely by the implementation of a gamification concept. However, an increase in the number of daily active users can be related to a change in product features, for example, a gamification concept. Depending on the objective of the company, various customer motivations might be identified as relevant. The subsequent step requires a precise target group analysis, including the definition of specific player types. A gamified business solution may consist of a combination of different player types. Therefore, it is important to understand which share of the business solution each player type has. Understanding customer motivation and player types enable the integration of appealing gamification elements, which will be the next step of the process.

The choice of suitable gamification elements is based on brainstorming. From a qualitative point of view, the brainstormed gamification elements need to be ranked according to their emotional effect on the customer. E4 calls this the reverse engineering process. From a quantitative point of view, the brainstormed elements need to be ranked according to budget, time, and effort for implementation. Consequently, qualitative and quantitative elements can exclude each other. The interconnection of the individual gamification elements will be based on the customer flow and therefore all customer touchpoints that have the potential to provide a gamified experience. The gamification strategy depends on one or multiple currencies that represent the weighting of individual gamification elements.

Above all, this first section is characterized by continuous testing. Only by frequently validating and adjusting the individual development steps, a customized and suitable gamification concept can be found.

\section{Milestone 2: Implementation of the gamification concept}

The implementation of gamification elements tries to enhance the customer experience on the one hand, while not disrupting the business solution features on the other hand. The findings show that gamification concepts and the underlying technology are independent. Only in the case of a digital solution, it is important to find a format that allows the gamification concepts to be integrated into the underlying system landscape.

Section B: Development steps after the implementation

The second step of the development of the cross-industry process chart involves evaluation, adaptation, testing, and reimplementation. The evaluation covers the assessment of relevant data, such as user experience and user interface data, as well as the measurement according to the company objective. If the data does not meet the expectations or an update of the gamification concept is pending, adaptions and re-testing need to be made. The four steps build an iterative improvement process that needs to be applied in regular frequencies after the gamification concept is initially implemented. This will prevent the gamification concept to become outdated.

\section{Conclusion}

The results from the expert interviews highlight the great potential of using gamification embedded in the business solutions of the mobility industry, as it is a key driver for customer loyalty and retention. Furthermore, since any gamification concept targets customer emotions, which are triggered by intrinsic motivation, it is not limited to the mobility industry. Based on the input of the experts, the authors created a cross-industry process chart that guides the development of a customer loyaltyfocused gamification concept.

According to that, gamification development teams need to execute a reverse engineering process, that targets customer motivation by integrating a suitable gamification strategy aligned with the company objective. Additionally, the development of a customer loyalty-focused gamification concept is based on an iterative improvement process. The findings reveal that 
gamified business solutions require to be frequently updated because customers individually choose business solutions that lead to the most pleasure.

However, the author acknowledges that the research findings are limited due to the number of different experts. This is why there is no specific solution for the development process of a gamification concept in the mobility industry given. As a result, the developed cross-industry process chart cannot be regarded as an evolutional stage for all industries alike. Instead, it provides a generic overview and can be used as a starting point for further research.

\section{References}

Arshad, M., Baharun, R., \& Zaidin, N. (2019). Goal-setting theory and gamification relationship in increasing mobile fitness apps engagement: A conceptual discussion. Journal of Business and Social Review in Emerging Economies, 5(1), 155-163. https://doi.org/10.26710/jbsee.v5i1.548

Costello, H. (2019). Gamification market to reach more than $\$ 32$ billion by 2025 -analysis by size, revenue, recent developments, opportunities, key trends, and business strategy. Retrieved from https://www.globenewswire.com/news-release/2019/07/30/1893406/0/en/Gamification-Market-to-ReachMore-Than-32-Billion-by-2025-Analysis-by-Size-Revenue-Recent-Developments-Opportunities-KeyTrends-and-Business-Strategy-Orbis-Research.html

Deterding, S. (2019). Gamification in management: Between choice architecture and humanistic design. Journal of Management Inquiry, 28(2), 131-136. https://doi.org/10.1177/1056492618790912

Draper, S. W. (1999). Analyzing fun as a candidate software requirement. Personal Technologies, 3(3), 117-122. https://doi.org/10.1007/BF01305336

Eppmann, R., Bekk, M., \& Klein, K. (2018). Gameful experience in gamification: Construction and validation of a gameful experience scale. Journal of Interactive Marketing, 43(2018), 98-115. https://doi.org/10.1016/j.intmar. 2018.03.002

Fitzgerald, C., Avramakis, E., Anchen, J., \& Raverkar, A. K. (2019). Mobility ecosystems: Striving towards a seamless interface for customers. Retrieved from https://www.swissre.com/institute/research/topics-and-riskdialogues/digital-and-technology/mobility-ecosystems.html

Gupta, A., \& Gomathi, S. (2017). A review on gamification and its potential to motivate and engage employees and customers: Employee engagement through gamification. International Journal of Sociotechnology and Knowledge Development, 9(1), 42-52. https://doi.org/10.4018/IJSKD.2017010103

Huotari, K., \& Hamari, J. (2017). A definition for gamification: anchoring gamification in the service marketing literature. Electronic Markets, 27(1), 21-31. https://doi.org/10.1007/s12525-015-0212-z

Hwang, J. (2018). Embracing fun in customer relationship management: The value of gamified loyalty programs. In Summer American Marketing Association Conference. Boston.

Kim, K., \& Ahn, S. J. (2017). The role of gamification in enhancing intrinsic motivation to use a loyalty program. Journal of Interactive Marketing, 40, 41-51. https://doi.org/10.1016/j.intmar.2017.07.001

Kortum, K., Schönduwe, R., Stolte, B., \& Bock, B. (2016). Free-Floating Carsharing: City-Specific Growth Rates and Success Factors. Transportation Research Procedia, 19, 328-340. doi: 10.1016/j.trpro.2016.12.092

Nobre, H., \& Ferreira, A. (2017). Gamification as a platform for brand co-creation experiences. Journal of Brand Management, 24(4), 349-361. https://doi.org/10.1057/s41262-017-0055-3

Noorbehbahani, F., Salehi, F., \& Jafar Zadeh, R. (2019). A systematic mapping study on gamification applied to e-marketing. Journal of Research in Interactive Marketing, 13(3), 392-410. https://doi.org/10.1108/jrim-082018-0103

Paharia, R. (2013). Loyalty 3.0: How to revolutionize customer and employee engagement with big data and gamification. New York: McGraw-Hill Education

Peinen, A. V., Bohmer, A. I., \& Lindemann, U. (2018). System Dynamics as a Tool for Data Driven Business Model Design in the Context of Autonomous Ride 
Hailing. 2018 IEEE International Conference on Engineering, Technology and Innovation (ICE/ITMC). doi: 10.1109/ice.2018.8436306

Saunders, M., Lewis, P., \& Thornhill, A. (2016). Research methods for business students (7th ed.). Harlow: Pearson Education Limited

Sever, N. S., Sever, G. N., \& Kuhzady, S. (2015). The Evaluation of potentials of gamification in tourism marketing communication. International Journal of Academic Research in Business and Social Sciences, 5(10), 188202. https://doi.org/10.6007/ijarbss/v5-i10/1867

Sigala, M., Toni, M., Renzi, M. F., Pietro, L. Di, \& Mugion, R. G. (2019). Gamification in Airbnb: Benefits and risks. E-Review of Tourism Research, 16(2-3), 24-32.

Xi, N., \& Hamari, J. (2019). The Relationship Between Gamification, Brand Engagement and Brand Equity. Proceedings of the 52nd Hawaii International Conference on System Sciences. doi: 10.24251/hicss.2019.099

Xin, O. W., Zuo, L., Iida, H., \& Aziz, N. (2018). Gamification effect of loyalty program and its assessment using game refinement measure: Case study on Starbucks. Lecture Notes in Electrical Engineering, 488, 161-171. https://doi.org/10.1007/978-981-10-8276-4_16

Zhao F., \& Guo D. (2019) Rewards in Gamification. In: Fang X. (eds) HCI in Games. HCII 2019. Lecture Notes in Computer Science, 11595. Cham: Springer 